\title{
ANALISIS KESEHATAN LAPORAN KEUANGAN PERBANKAN SYARIAH DENGAN MENGGUNAKAN METODE RGEC (STUDY KASUS PADA BANK JATENG SYARIAH)
}

\author{
Siti Nailatul Chofifah \\ Universitas Islam Negri Sunan Ampel Surabaya \\ Email : naylachofifah@gmail.com
}

\begin{abstract}
Banking itself is a financial institution as a channel of funds between parties who have excess funds and those who need funds. Meanwhile, Islamic banks are banks that operate based on Islamic principles or in accordance with the provisions of the Qur'an and Hadith. The purpose of this study was to determine the health of Islamic Central Java banks in the 2015-2019 period using the RGEC method (risk profile, good corporate governance, earnings, and capital). For indicators, the risk profile is measured through the credit ratio (NPF) and liquidity ratio (FDR). As for GCG, it is calculated through the ratio of PDN. The Eraning indicator can be measured based on the ratio of ROA, ROE, NI, and BOPO. And for the last is Capital analysis using the $C A R$ ratio. At the Islamic Central Java bank, the results from this analysis were ranked 2 when viewed from the overall RGEC (risk profile, good corporate governance, earnings, and capital). Therefore, the Islamic Central Java bank has been considered good in every performance.
\end{abstract}

Keywords: Islamic Central Java Bank, Health Bank, RGEC

\begin{abstract}
Abstrak: Perbankan sendiri merupakan lembaga keuangan sebagai penyalur dana antara pihak yang kelebihan dana dan piha yang membutuhkan dana. Sedangkan bank syariah adalah bank yang beroprasi berdasarkan dengan prinsip islami atau sesuai dengan ketentuan al-qur'an dan hadist. Tujuan dari penelitian ini adalah untuk mengetahui kesehatan bank JATENG syariah pada periode 2015-2019 dengan menggunakan metode RGEC (risk profile, good corporate governance, earning, dan capital). Untuk indikato Risk profile diukur melalui rasio krdit (NPF) dan rasio likuiditas (FDR). Sedangkan untuk GCG menghitung melalui rasio PDN. Untuk indicator Eraning dapat diukur berdasrakan rasio ROA, ROE, NI, dan BOPO. Dan untuk yang terakahir adalah analisis Capital menggunakan rasio CAR. Pada bank JATENG syariah mendapatka hasil dari analisis ini mendapatkan peringkat 2 jika dilihat dari keseluruhan RGEC (risk profile, good corporate governance, earning, dan capital). Maka dari itu bank JATENG syariah dianggap sudah baik dalam setiap melakukan kinerjanya.
\end{abstract}

Kata Kunci: Bank JATENG syariah, Kesehatan Bank, RGEC

\section{PENDAHULUAN}

Perbankan syariah, perbankan syariah sudah mulai meluas dikalangan masyarakat bahkan tidak asing lagi dan masyarakat percayabank syariah sebagai bank bebas dari unsure riba yang dilarang dalam agama islam. Perbankan sendiri merupakan 
lembaga keuangan sebagai penyalur dana antara pihak yang kelebihan dana dan piha yang membutuhkan dana. Sedangkan bank syariah adalah bank yang beroprasi berdasarkan dengan prinsip islami atau sesuai dengan ketentuan al-qur'an dan hadist.

Bank syariah membuat agar berbeda dengan bank konvensional yaitu dengan menerapkan larangan terhadap riba dalam semua transa. Dalam melaksanakan perannya bank sebagai penyalur dana antara pihak masyarakat yang memiliki dana antara masyarakat yang membutuhkan dana. Bank disini hanya sebagai penyalur atau perantara antara pihak yang bersangkutan. Dalam hal ini bank juga harus memperhatikan kepeuasan pelanggan atau kepercayaan seorang nasabah. Karena tidak ada bank yang beroprasi dengan sukses kecuali dengan kepercayaan dan kayakinan masyarkat terhadap bak tersebut (samanto \& hidayah, 2020).

Untuk membangun kepercayaan suatu masyarakat bank memberikan informasi dan disiapkan secara detail dalam laporan keuangan berdasarkan ketentuan yang berlaku. Laporan keuangan juga digunakan untuk menilai kesehatan suatu bank. Kesehatan bank juga bisa dikatakan sebagaiman bank itu melakukan kegiatan operasionalnya normal atau mampu dalam menjalankan semua operasionalnya sesuai dengan cara yang sesuai dengan peraturan perbankan.

Kesehata suatu bank juga penting bagi semua kalangan yang bersangkutan, baik pemilik, dan pengelolah bank, masyarakat penguna layanan bank, maupun BI yang berperan membinan dan pengawas perbankan. Maka dari itu dari semua kalangan yang berperan harus melakukan penilaian terhadapa kinerja kesehatan bank dengan melihat laporan keuangan yang telah diterbitkan oleh pihak bank (andraini, 2019)

Penilaian kesehatan bank dapat dilakukan dengan menggunakan metode RGEC (Risk profile, Good corporate, Governance, Earning, dan Capital) (agustina, 2017). Dalam hal ini untuk menghitung kesehatan bank penulis tertarik ingin mengambil pada bank JATENG, karena bank JATENG sendiri merupakan bank milik pemerintah yang menjalankan operasionalnya berbasisi syariah yang mempu berkembang secara signifikan walaupun juga menjalankan yang berbasisi konvensional. Dalam hal ini bisa diliat dengan meningkatnya keuntungan dari tahun ke tauhun.

Permasalahn pada penelitian ini adalah bagaimana tingkat kesehatan bank JATENG syariah di tahun 2015-2019 dengan menggunan metode RGEC. Penelitian ini bertujuan untuk mengetahun bagaiamana kesehatan bank JATENG syariah. Penelitian ini menganalisis perkembangan dari 5 tahun yaitu antara 2015 sampai dengan 2019 . 


\section{TINJAUAN LITERATUR}

\section{Perbankan Syariah}

Didalam UU No 21 tahun 2008 tentang perbankan syariah dijelaskan bahwa perbankan syaraiah merupakan perbankan yang dalam kegiatanya menjalankan prinsip syariah dan terdiri dari dua jenis yaitu bank umum syariah dan bank pembiayaan rakyat syariah. Di perbankan syariah semua kegiatan usahanya berdasarkan dengan al-qur'an, hadist, qyas, bahkan dalam hal akadnya berdasarkan hal yang islami. Bank syariah juga bank yang beroprasi menjauhi unsure riba tapi menjalankanya berdasarkan bagi hasil, karena didalam al-qu'an juga disebutkan bahwa dalam bermuamalat harus menjauhi unsure riba dalam setiap prakteknya (fahmi, 2015).

Seperti halnya yang dijelaskan dalam al-qur'an surat Ali Imran: 130 yang menjelaskan tentang larangan terhadap riba yang berbunyi:

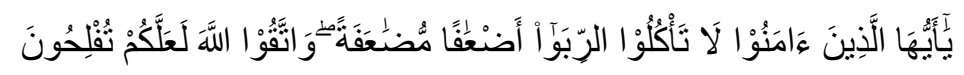

Artinya: Hai orang-orang yang beriman, Janganlah kamu memakan riba dengan berlipat ganda, dan bertakwalah kamu kepada Allah supaya kamu mendapat keberuntungan.

Jadi dapat diambil kesimpulan bahwa bank syariah merupakan bank yang dalam semua kegiatan atau aktivitasnya meninggalkan perkara riba, maka dari itu bank syariah menghindari bunga yang dianggap sebagai riba. Bank syariah mengganti system bunga dengan bagi hasil.

Dalam bank syariah mereka mempunyai tujuan, diantaranya sebagai berikut:

a. Melakukan kegiatan ekonomi terutama dalam bermuamalat sesuai dengan syariah islam, seperti pada perbankan agar terhindar dari unsure riba

b. Untuk membuntikan bahwa konsep perbankan syariah itu sesuai dengan syariah islam dalam menjalankan segala kegiatanya agar bisa beroprasi dan berkembang melebihi bank lainya.

c. Meratakan pendapatan melalui jalur investasi agar menciptakan keadilan dalam bidang ekonomi agar tidak terjadi prokontra antara pemilik modal dengan oaring yang membutuhkan modal

d. Menanggukangi kemiskinan, dengan cara melakukan program pembinaan consumen, pengembangan modal kerja, dan pengembangan usaha bersama

e. Menjaga kestabilan ekonomi moneter yang bisa diakibatkan adanya inflasi

f. Yang terkahir yaitu agar masyarakat tidak ketergantungan dengan bank nonsyariah (sudarsono, 2008). 
Niqosiya: Journal of Economics and Business Research

Vol. 1 No. 1, Januari-Juni 2021: 94-109

\section{Kesehatan Bank}

Kesehatan atau kondisi keuangan suatu bank biasanya digunakan untuk menilai atau mengevaluasi kondisi kinerja bank dalam penerapan prinsip kehati-hatian terhadap apa yang sudah ada pada ketentuan yang berlaku yang biasanya dilakukan oleh pihak terkait diantarnya, pemilik, manajemen bank, bank pemerintah, dan nasabah atau pengguna jasa bank.

Kesehatan bank adalah dimana bank itu mampu melaksanakan kegiatan operasionalnya secara normal dan bisa memenuhi kewajibannya secara benar dan baik berdasarkan pertaruan perbankan yang berlaku (umiyati \& permata, 2015). Penilaian suatu kesehatan bank merupakan hasil akhir dari penilaian pengawasana perbankan yang yang menunjukkan kinerja perbankan nasional. Dalam penilaian tingkat kesehatan bank manajemn bank harus memiliki prinsip berorientasi resiko, matrealistis dan signifikansi serta komprehensif serta terstrktur (Peraturan bank Indonesia No.13/1/PBI/2011 dan SE BI No.13/24/DPNP).

Bagi para investor ataupun para nasabah informasi mengenai penilaian tentang kesehatan bank merupakan informasi yang penting agar biasa menggambarkan bagaimana kondisi kesehatan bank tersebut. Jika suatu bank tersebut memiliki nilai kesehatan bank yang baik maka bank tersebut memiliki nilai positif bagi para investor, akan tetapi jika kondisi keuangan bank tersebut menurun maka bagi para investor akan menilai jelek bank tersebut dan reputasi bank tersebut menurun.

Pada peraturan bank Indonesia (No.13/PBI/2011) bank Indonesia mengeluarkan edaran tentang penilaian tingkat kesehatan bank dengan menggunakan pendekatan resiko yang terdiri dari empat factor diantaranya: Risk Profile (Profil resiko), Good Corporate Governance (GCG), Earnings (Rentabilitas), dan Capital (Permodalan) yang biasa disebut dengan istilah metode RGEC. Metode RGEC ini digunakan untuk penialain tingkat kesehatan bank sejak 1 januari 2012.

Pada setiap perbankan harus bisa mempertahankan tingkat kesehatan bank agar masyarakat tetap bisa mempertahankan kepercayaan terhadap bank terutama pada bank syariah. Agar bisa mempertahankan kepercayaan masyarakat bank harus bisa mengoptimalkan nilai kinerja baik secara operasionalnya, aset, dan intern yang ada pada bank tersebut. 


\section{METODE PENELITIAN}

Pada penelitian Analisis kesehatan laporan keuangan perbankan syariah ini penulis mengambil contoh yang dilakukan pada bank JATENG syariah. Pengamatan penelitian ini dilakukan dalam rentang waktu lima tahun yaitu antara 2015 sampai dengan 2019.

Pada penelitian ini sumber datanya berupa data sekunder. data sekunder merupakan data yang diperoleh secara tidak langsung (wiroatmodjo, 2009). Data yang digunakan pada penelitian ini terdiri dari dari data internal pada bank Jateng yang berupa laporang keuangan bank Jateng pada periode 2015 sampai dengan 2019.

Metode pengumpulan data yang berkaitan dengan masalah dalam penulisan dilakukan menggunakan metode dokumentasi, metode dokumentasi merupakan metode pengumpulan data secara mengutip atau mencatat dari data harian ataupun laporan keuangan serta melalui website Bank JATENG untuk memperoleh laporan keuangan.

Dalam menganalisis kesehatan laporan keuangan perbankan syariah pada Bank JATENG syariah dapat menngunakan teknik analisis data dengan metode RGEC, karena sesuai dengan peraturan bank Indonesia tentang penilaian kesehatan bank umum. Metode RGEC merupakan penilaian tingkat kesehatan bank yang berbasisi resiko (surya, qonita, \& magfiroh, 2019). Penialian terhadap factor RGEC terdiri dari:

1. Risk profile (Prifil resiko)

Penilaian terhadap resiko kualitas terhadap penerapan manajemen resiko di dalam operasional bank dapat dilakukan dengan 8 tahapan resiko yaitu resiko kredit, pasar, likuiditas, operasional, hukum, stratejik, kepatuhan dan reputasi. Pada penelitian ini dalam mengukur risk profile dapat menggunakan dua factor yaitu NPF (non performing finance) dan FDR (financing to deposit ratio). Menghitung dengan rumus:

a. Rumus NPF (Non Performing Financing)

$$
\mathrm{NPF}=\frac{\text { kredit bermasalah }}{\text { total kredit }} \times 100 \%
$$

Tabel 1. Klasifikasi peringkat NPF

\begin{tabular}{ccc}
\hline Peringkat & Nilai Komposit & Predikat \\
\hline 1 & $\mathrm{NPF} \geq 2 \%$ & Sangat baik \\
\hline 2 & $2 \% \leq \mathrm{NPF}<5 \%$ & Sehat \\
\hline 3 & $5 \% \leq \mathrm{NPF}<8 \%$ & Cukup sehat \\
\hline 4 & $8 \% \leq \mathrm{NPF}<12 \%$ & Kurang sehat \\
\hline 5 & $\mathrm{NPF} \leq 12 \%$ & Tidak sehat \\
\hline
\end{tabular}


b. Rumus FDR (Financing To Depositite Ratio)

$$
\text { FDR }=\frac{\text { Jumlah kredit yang diberikan }}{\text { total dana pihak ketiga }} \times 100 \%
$$

Tabel 2. Klasifikasi peringkat FDR

\begin{tabular}{ccc}
\hline Peringkat & Nilai Komposit & Predikat \\
\hline 1 & $50 \% \leq$ FDR $<75 \%$ & Sangat baik \\
\hline 2 & $75 \% \leq$ FDR $<85 \%$ & Sehat \\
\hline 3 & $85 \% \leq$ FDR $<100 \%$ & Cukup sehat \\
\hline 4 & $100 \% \leq$ FDR $<120 \%$ & Kurang sehat \\
\hline 5 & FDR $\leq 120 \%$ & Tidak sehat \\
\hline
\end{tabular}

\section{Good Corporate Governance}

Suatu mekanisme tata kelola organisasi secara baik melakukan pengelolahan sumber daya organisasi secara efisien, efektif dan menerepkan prinsip akuntabilitas, pertanggung jawaban, adil dalam memncapai tujuan. Dapat diperoleh dengan rumus PDN (Posisi Devisa Netto):

$$
\mathrm{PDN}=\frac{\text { selisih aset dan liabilitas valas }}{\text { total } \text { modal }} \times 100 \%
$$

Tabel 3. Klasifikasi peringkat PDN

\begin{tabular}{clc}
\hline Peringkat & \multicolumn{1}{c}{ Nilai Komposit } & Predikat \\
\hline 1 & Tidak ada pelangggaran rasio PDN & Sangat sehat \\
\hline 2 & $\begin{array}{l}\text { Tidak ada pelanggaran rasio PDN namun } \\
\text { Pernah Melakukan pelanggaran dan telah } \\
\text { diselesaikan }\end{array}$ & Cukup sehat \\
\hline 3 & $\begin{array}{l}\text { pelanggaran rasio PDN }>0 \% \text { Sampai } \\
\text { dengan }<10 \%\end{array}$ & sehat \\
\hline 4 & $\begin{array}{l}\text { pelanggaran rasio PDN }>10 \% \text { Sampai } \\
\text { dengan <25\% }\end{array}$ & Kurang sehat \\
\hline 5 & Pelanggaran PDN lebih dari 25\% & Tidak sehat \\
\hline
\end{tabular}

\section{Earnings}

Rentabilitas merupakan alat ukur untuk mengukur tingkat efisiensi usaha dan profitabilitas yang dicapai oleh bank yang bersangkutan (ROA, ROE, NI, $\mathrm{BOPO})$, dengan rumus:

a. Rumus ROA (Return On Assets)

$$
\mathrm{ROA}=\frac{\text { laba sebelum } \text { pajak }}{\text { rata-rata total aset }} \times 100 \%
$$


Tabel 4. Klasifikasi peringkat ROA

\begin{tabular}{ccc}
\hline Peringkat & Nilai Komposit & Predikat \\
\hline 1 & $\mathrm{ROA} \geq 2 \%$ & Sangat sehat \\
\hline 2 & $1,26 \% \leq \mathrm{CAR}<1,5 \%$ & sehat \\
\hline 3 & $0,51 \% \leq \mathrm{CAR}<1,25 \%$ & Sehat \\
\hline 4 & $0 \% \leq \mathrm{CAR}<0,5 \%$ & Cukup Kurang sehat \\
\hline 5 & $\mathrm{ROA}<0 \%$ & Tidak sehat \\
\hline
\end{tabular}

b. Rumus ROE (Return On Equity)

$$
\mathrm{ROE}=\frac{\text { laba setelah } \text { pajak }}{\text { rata-rata total } \text { modal }} \times 100 \%
$$

Tabel 5. Klasifikasi Peringkat ROE

\begin{tabular}{ccc}
\hline Peringkat & Nilai Komposit & Predikat \\
\hline 1 & ROE $\geq 20 \%$ & Sangat sehat \\
\hline 2 & $12,5 \% \leq \mathrm{CAR}<20 \%$ & sehat \\
\hline 3 & $5 \% \leq \mathrm{CAR}<12,5 \%$ & Sehat \\
\hline 4 & $0 \% \leq \mathrm{CAR}<5 \%$ & Cukup Kurang sehat \\
\hline 5 & ROA $<0 \%$ & Tidak sehat \\
\hline
\end{tabular}

c. Rumus NI (Net Imbalan)

$\mathrm{NI}=\frac{\text { pendapatan imbalan }}{\text { rata-rata aset produktif }} \times 100 \%$

Tabel 6. Klasifikasi Peringkat NI

\begin{tabular}{ccc}
\hline Peringkat & Rasio & Predikat \\
\hline 1 & $\mathrm{NI} \geq 6,5 \%$ & Sangat sehat \\
\hline 2 & $2,01 \% \leq \mathrm{NI}<6,5 \%$ & sehat \\
\hline 3 & $1,5 \% \leq \mathrm{NI}<2 \%$ & Sehat \\
\hline 4 & $0 \% \leq \mathrm{NI}<1,49 \%$ & Cukup Kurang sehat \\
\hline 5 & $\mathrm{NI}<0 \%$ & Tidak sehat \\
\hline
\end{tabular}

d. Rumus BOPO

$\mathrm{BOPO}=\frac{\text { biaya operasional }}{\text { pendapatan operasional }} \times 100 \%$

Tabel 7. Klasifikasi peringkat BOPO

\begin{tabular}{ccc}
\hline Peringkat & Rasio & Predikat \\
\hline 1 & Kurang dari $88 \%$ & Sangat sehat \\
\hline 2 & $89 \%$ sampai dengan $93 \%$ & sehat \\
\hline
\end{tabular}


Niqosiya: Journal of Economics and Business Research

Vol. 1 No. 1, Januari-Juni 2021: 94-109

\begin{tabular}{ccc}
\hline Peringkat & Rasio & Predikat \\
\hline 3 & $94 \%$ sampai dengan $96 \%$ & Sehat \\
\hline 4 & $97 \%$ sampai dengan 100\% & Cukup Kurang sehat \\
\hline 5 & Lebih dari 100\% & Tidak sehat \\
\hline
\end{tabular}

4. Capital

Capital Adequacy Ratio (CAR) merupakan rasio yang digunakan untuk mengukur kecukupan modal yang dimiliki oleh suatu bank untuk menunjang aktiva yang menghasilkan resiko. Rasio kecukupan ini menunjukkan perbankan untuk menyediakan dana yang digunakan mengatasi resiko kerugian. Untuk mencari factor capital harus menghitung pemodalan yang dimiliki bank dengan cara menghitung menggunakan rumus CAR yaitu: (surya, safitri, \& basya, analisi tingkat kesehatan bank melalui pendekatan RGEC (risk profile, good corporate, governance, earning, capital), 2019)

$$
\mathrm{CAR}=\frac{M O D A L}{(A T M R)} \times 100 \%
$$

Tabel 8. Klasifikasi peringkat CAR

\begin{tabular}{ccc}
\hline Peringkat & Nilai komposit & predikat \\
\hline 1 & $\mathrm{CAR} \geq 12 \%$ & Sangat sehat \\
\hline 2 & $9 \% \leq \mathrm{CAR}<12 \%$ & Sehat \\
\hline 3 & $8 \% \leq \mathrm{CAR}<9 \%$ & Cukup sehat \\
\hline 4 & $6 \% \leq \mathrm{CAR}<8 \%$ & Kurang sehat \\
\hline 5 & $\mathrm{CAR} \leq 6 \%$ & Tidak sehat \\
\hline
\end{tabular}

\section{HASIL DAN PEMBAHASAN}

\section{Analisis Kesehatan Bank JATENG Syariah}

\section{Analisis Risk profile (Profil Resiko)}

Berdasarkan data dari laporan keuangan dan perhitungan penulis dari periode 2015 sampai dengan 2019 dapat dirangkum pada tabel berikut:

Tabel 8. NPF Bank JATENG Syariah Periode 2015-2019

\begin{tabular}{c|c}
\hline \multicolumn{2}{|c}{$\mathrm{NPF}$} \\
\hline 2015 & $0,22 \%$ \\
\hline 2016 & $0,21 \%$ \\
\hline 2017 & $0,06 \%$ \\
\hline 2018 & $0,08 \%$ \\
\hline 2019 & $0,32 \%$ \\
\hline
\end{tabular}

Berdasarkan pada Tabel 8 diketahui NPF pada bank JATENG syariah pada tahun 2015 mengalami kenaikan sejumlah 0,2, pada tahun 2016 sedikit mengalami 
penurunan yaitu pada 0,21, sedangkan pada tahun 2017 NPF bank JATENG syariah mengalami penurunan yang cukup banyak yaiti 0,06. Pada saat 2018 bank JATENG syariah mengalami kenaikan sedikit dengan 0,08 . Sedangkan yang terakhir pada tahun 2019 sebesar 0,32. Sehingga pada tahun 2015 sampai dengan 2019 bisa dikatakan sangat baik meskipun mengalami naik turun karena nilai pada rentang tahun 2015 sampai dengan 2019 memiliki nilai kurang dari 2\%

Tabel 9. FDR Bank JATENG Syariah Periode 2015-2019

\begin{tabular}{cc}
\hline \multicolumn{2}{c}{ FDR } \\
\hline 2015 & $115,10 \%$ \\
\hline 2016 & $59,85 \%$ \\
\hline 2017 & $78,90 \%$ \\
\hline 2018 & $115,85 \%$ \\
\hline 2019 & $110,57 \%$ \\
\hline
\end{tabular}

Berdasarkan data dari bank JATENG syariah dapat diperoleh kesimpulan tentang FDR pada rentang waktu 2015 sampai dengan 2019. Pada tahun 2015 bank JATENG syariah mendapatkan rasio yang kurang sehat karena memiliki nilai diatas $100 \%$ dan kurang dari $120 \%$ yaitu sebesar $115.10 \%$. pada tahun 2016 mendapatkan predikat sqngat sehat karena nilai rasionya dibawah $75 \%$ yaitu sebesar 59,85\%. Pada tahun selanjutnya 2017 mendapatkan predikat sehat yaitu sebesar 78,90\% dikatakan sehat karena memiliki nilai kurang dari $85 \%$ dan ebih dari $75 \%$. Pada berikutnya yaitu tahun 2018 mengalami kenaikan yang cukup derastis yang mengakibatkan mendaptkan predikat yang kurang sehat yaitu sebesar 115,85\%. Pada tahun selanutnya yaitu 2019 menglami rasio yang kurang sehat yaitu sebesar $110,57 \%$ dikatakan tidak sehat dikarenakan kurang dari $120 \%$ dan lebih dari $100 \%$.

\section{Analisis Good Coporate (GCG)}

Tabel 9. PDN Bank JATENG Syariah Periode 2015-2019

\begin{tabular}{cc}
\hline \multicolumn{2}{c}{ PDN } \\
\hline 2015 & $0,90 \%$ \\
\hline 2016 & $1,15 \%$ \\
\hline 2017 & $0,36 \%$ \\
\hline 2018 & $0,22 \%$ \\
\hline 2019 & $0,17 \%$ \\
\hline
\end{tabular}

Berdasarkan Tabel 9 yang diambil dari data laporan keuangan bank JATENG syariah dapat dianalisis GCG (Good coporate governance) sejak tahun 2015 sampai 
dengan 2019 bisa dikatakan cukup sehat karena hasil dari PDN lebih besar dari 0\% dan kurang dari 10\%, yaitu pada tahun 2015 nilai PDN sebesar 0,905. Sedangkan pada tahun 2016 mengalami kenaikan sebesar 1,15\%. Akan tetapi pada tahun 2017 mengalami penurunan yaitu sebesar 0,36 namun masih lebih besar dari pada $0 \%$. Pada tahun berikutnya semakin mengalami penurunan yaitu sebesar 0,22\%. Dan tahun selanjutnya mengalami penurunan sejumlah 0,17 di tahun 2019. Jadi dapat dikatan bank JATENG syariah selama 5 tahun terakhir ini banyak mengalami penurunan maka dapat digolongkan dalam kategori cukup sehat.

\section{Analisis Earning (Rentabilitas)}

Dalam komponen analisis Earning diukur melalui laporan keuangan berdasarakan pada ROA, ROE, NI, dan BOPO

Tabel 10. ROA Bank JATENG Syariah Periode 2015-2019

\begin{tabular}{cc}
\hline \multicolumn{2}{c}{ ROA } \\
\hline 2015 & $1,47 \%$ \\
\hline 2016 & $1,62 \%$ \\
\hline 2017 & $2,23 \%$ \\
\hline 2018 & $2,99 \%$ \\
\hline 2019 & $2,91 \%$ \\
\hline
\end{tabular}

Berdasrakan data dari laporan keuangan yang dirangkum oleh penulis dalam tabel diatas, pada periodee tahu 2015 sampai dengan 2019. Berdasrakan tahun 2015 yang ada ditabel diperoleh nilai hasil ROA sejumlah 1,47\% yaitu dalam keadaan sehat karena kurang dari 1,5\% dan lebih dari 1,25\%. Pada tahun 2016 memiliki nilai sebesar 1,62\% mempunyai peringkat 1 karena dalam predikat yang sangat sehat karena kurang dari 2\% dan lebih dari 1,5\%. Sedangkan di tahun 2017, 2018, dan 2019 mengalami kenaikan yang bisa dikategorikan dalam keadaan sangat sehat karena memiliki nilai yang lebih dari $2 \%$ yaitu $2,23 \%, 2,99 \%$, dan $2,91 \%$.

Tabel 11. ROE Bank JATENG Syariah Periode 2015-2019

\begin{tabular}{cc}
\hline \multicolumn{2}{c}{ ROE } \\
\hline 2015 & $28,59 \%$ \\
\hline 2016 & $23,17 \%$ \\
\hline 2017 & $22,08 \%$ \\
\hline 2018 & $22,64 \%$ \\
\hline 2019 & $17,67 \%$ \\
\hline
\end{tabular}


Dari hasil analisis rasio ROE oleh bank JATENG syariah mengalami pasang surut. Pada tahun 2015, 2016,2017, dan 2018 mendapatkan predikat sangat baik karena memiliki nilai diatas $20 \%$ yaitu dengan nilai sebesar 28,59\%, 23,17\%, 22,08\%, dan 22,64\%. Sedangkan ditahun 2019 mengalami penurunan yaitu sejumlah 17,67\% yang dikategorikan sehat.

Tabel 12. NI Bank JATENG Syariah Periode 2015-2019

\begin{tabular}{cc}
\hline \multicolumn{2}{c}{ NI } \\
\hline 2015 & $7,25 \%$ \\
\hline 2016 & $7,01 \%$ \\
\hline 2017 & $5,73 \%$ \\
\hline 2018 & $6,75 \%$ \\
\hline 2019 & $5,88 \%$ \\
\hline
\end{tabular}

Pada tahun 2015 sampai dengan 2019, NI atau Net Imbalan pada bank JATENG syariah dapat dianalisis sebagai berikut, pada tahu 2015, 2016, dan 2018 diperoleh hasil NI pada rasio keuangan sejumlah 7,25\%,7,01\%, dan 6,75\% yang dikategorikan dalam peringkat yang sangat bagus karena nilainya lebih dari 6,5\%. Sedangkan ditahun 2017 dan 2019 mengalami penurunan dan dikategorikan dalam predikat yang sehat karena nilainya kurang dari dari 6,5\% dan lebih besar dari 2,01\% yaitu sebesar 5,73\% dan $5,88 \%$

Tabel 13. BOPO Bank JATENG Syariah Periode 2015-2019

\begin{tabular}{cc}
\hline \multicolumn{3}{c}{ BOPO } \\
\hline 2015 & $76,05 \%$ \\
\hline 2016 & $76,18 \%$ \\
\hline 2017 & $74,60 \%$ \\
\hline 2018 & $73,87 \%$ \\
\hline 2019 & $80,65 \%$ \\
\hline
\end{tabular}

Pada analisis BOPO ini berdasarkan hasil rasio keuangan bank JATENG syariah pada tahun 2015 sampai dengan 2019 dapat dikategorikan dalam predikat yang sangan sehat karena menunjuukan nilai yang kurang dari $88 \%$ dapat dilihat ditabel bahwa nilai BOPO pada tahun 2015 sampai dengan 2019 adalah kurang dari 88\%.

\section{Analisis Capital (Modal)}

Pada penialain rasio CAR berdasarkan tabel diatas dapat diketahui bahwa rasio CAR pada bank JATENG syariah dapat diketegorikan dalam pridikat yang sehat pada 
tahun 2015 sampai dengan 2019 karena memiliki nialai yang lebih dari 12\%, akan tetapi juga mengalami penurunan pada tahun 2015 sebesar 14,87\% meskipun mengalami penurunan tapi tetap bisa dikatakan dalam kategori predikat yang sangat sehat. Pada tahun 2016 dan 2017 mengalami kenaiakan yaitu bernilai 20,25\% dan 20,41\%, sedangkan pada tahun selnjutkanyaitu 2018 dan 2019 sedikit mengalami penurunan akan tetapi tidak mempengaruhi predikat yang sangat sehat yaitu berjumlah $18,31 \%$ dan $17,70 \%$.

Tabel 14. CAR Bank JATENG Syariah Periode 2015-2019

\begin{tabular}{cc}
\hline \multicolumn{2}{c}{ CAR } \\
\hline 2015 & $14,87 \%$ \\
\hline 2016 & $20,25 \%$ \\
\hline 2017 & $20,41 \%$ \\
\hline 2018 & $18,31 \%$ \\
\hline 2019 & $17,70 \%$ \\
\hline
\end{tabular}

\section{Tingkat Kesehatan Bank JATENG syariah}

Berdasarkan hasil analisis menggunakan metode RGEC pada bank JATENG syariah pada rentang waktu 2015 sampai dengan 2019, didapatkan hail sebagai berikut:

\section{Risk Profile (profil resiko)}

Untuk hasil perhitungan risiko kredit dan risiko likuiditas bank JATENG syariah dapat disimpulkan sebagai berukut: untuk analis risiko kredit bank JATENG syariah bisa dikatakan berdasa pada peringkat 1 yaitu bada posisi yang sangat sehat, karena nilai NPF pada tahun 2015 sampai dengan 2019 berada dalam posisi nilai kurang dari 2\%. Kemudian pada analisis FDR atau risiko likuiditas pada bank JATENG syariah berada pada tingkat 3 yaitu mendapatkan predikat yang kurang sehat pada tahun 2015 sampai dengan 2019, akan tetapi pada tahun 2016 dan 207 peringkat FDR berubah. Pada tahun 2016 peringkat dengan tingkat 1 yang disebut dengan prdikat yang sangat sehat karena nilainya kurang dari $75 \%$ yaitu sebesar 59,85\%. Sedangkan ditahun 2017 mendapatkan predikat yang sehat karena nilainya lebig dari $75 \%$ dan kurang dari $85 \%$ yaitu sebesar $78,90 \%$. Dari hasil analisis dapat disimpulkan bahwa bank JATENG syariah sudah dikategorikan bbahwa bank JATENG syariah sudah bisa melakukan kinerjanya yang baik, kana tetapi dalam mengatasi problem kredit macet bank JATENG syariah harus bisa meningkatkannya kembali agar para nasabah bisa memberikan kepercayaan yang baik. 


\section{Good Coporate (GCG)}

Pada analisis GCG pada bnak JATENG Syariah bisa dikategirikan dalam perikat ke 3 karena pada tahun 2015 samapi dengan dengan 2019 hasil dari rasio memiliki nilai komposit yang kurang dari 10\% dan lebih dari 0\% maka dari itu bisa diktehorikan sebagai predikat yang cukup sehat. Pada tahun 2015 memiliki nilai sebesar 0,90\%. Pada tahun 2016 memiliki nilai 1,15\%. Pada tahun 2017 memiliki nilai 0,36\%. Pada tahun 2018 berjumlah 0,22\%. Dan tahun 2019 memiliki nilai 0,17\%. Maka dari itu bank JATENG Syariah dapat dikategorikan cukup bisa menerapkan GCG, namun bank JATENG Syariah juga harus bisa memperbaiki agar menjadi yang lebih baik lagi secara efektif dan efisien.

\section{Earning (Rentabilitas)}

Dalam penilaian Erning pada bank JATENG Syariah menggunkan beberapa indicator rasiao. ROA (Return On Assets) pada tahun 2015 mengalami predikat yang sehat karena memiliki nilai kurang dari 1,5\% dana lebih dari 1,25\% maka dari itu mendapatkan peringkat ke-2, namun pada tahun selanjutnya yaitu 2016, 2017, 2018, 2019 disebut dalam kategori yang sangat sehat karena ditahun selanjutnya nilai kompositnya bank JATENG syariah mengalami kenaikan maka dari itu berkedudukan pada peringkat ke-1 yaitu bernilai sebesar 1,62\%, 2,23\%, 2,99\% dan 2,91\%. Indicator rasio ke dua yaitu ROE (Return On Equity) pada bank JATENG syariah di tahun 2015 sampai dengan 2018 dikategorikan dalam peringkat ke1kareena memiliki nilai yang lebih dari $20 \%$ maka dari itu bisa disebut dengan predikat yang sangat sehat dengan nilai yaitu untuk 2015 sebesar 28,59\% untuk tahun 2016 sebesar 23,17\%, tahun 2017 sebesar 22,08, dan tahun 2018 sebesar 22,64\%. Akan tetapi pada tahun 2019 nilai ROE pada bank JATENG syariah mengalami penurunan yang cukup derastis sehingga masuk dalam kategori sehat terletak pada peringkat ke-2 karena mempunyai nilai komposit sebesar $17,67 \%$ yang kurang dari $20 \%$ dan lebih dari $12,5 \%$. Indicator rasio ketiga yaiturasio nilai timbang (NI), Pada bank JATENG syariah pada tahun 2015, 2016, dan 2018 memiliki nialai rasio yang sangat bagus karena memiliki nilai yang lebih dari $6,5 \%$ dan terletak pada peringkat ke-1 dengan nilai, pada tahun 2015 sebesar 7,25\% pada tahun2016 sebesar 7,01\%, dan tahun 2018 sebesar 6,75\%. Sedangkat ditahun 2017 dan 2019 nilai NI pada bank JATENG syariah ini mengalami penurunan yaitu sebesar $5,73 \%$ dan $5,88 \%$ termasuk dalam predikat yang sehat karena nilai 
komposit dibawah $6,5 \%$ dan diatas $2,01 \%$ dikategorikan dalam peringkat ke-2. Indicator yang terakhir yaitu biaya operasional dan pendapatan operasional (BOPO). Pada indicator BOPO di bank JATENG Syariah ini berdasarkan tahun 2015 sampai dengan 2019 mengalami nilai komposit yang kurang dari 88\% karena semakinkecil nilai itu semakin sehat keaadaan bank tersebut, dan pada bank JATENG syariah ini berada pada peringkat ke-1 dengan predikat yang sangat sehat, yang mempunyai nilai indiakator, pada tahun 2015 sebesar 76,05\%, pada tahun 2016 sebesar 76,18\%, dan tahun 2017 sebesar 74,60\%, dan ditahun 2018 sebesar 73,87. Dan tahun 2019 sebesar 80,65\%. Dari beberapa indicator diatas dapat disimpukan bahwa bank JATENG syariah dalam mengelolah asset dengan baik.

\section{Capital (Modal)}

Pada analisis Capital pada bank JATENG Syariah menurut penilaian CAR bank JATENG syariah bisa dikategorikah pada peringkat ke-1 karena dalah keadaan yang sehat pada tahun 2015 samapi dengan 2019, meskipun dalam rentang waktu 5 tahun antara 2015 sampai dengan 2019 mengalami naik turun tapi tetap masih dalam keadaan yang sangat sehat karena memiliki rasio nilai yang lebih besar dari pada $12 \%$ maka dari itu dikategorikan dlam keadaan sangat sehat. Dengan demikian bahwa bank JATENG syariah memiliki moda yang sangat bagus untyk memenuhi segala kebutuhan dan kewajiban baik dalam segi usaha dan sebagai penutup bagi resikokerugian yang disebabkan perusahaan.

\section{KESIMPULAN}

Dapat diambil kesimpulan berdasarkan analisis RGEC (risk profile, good corporate governance, earning, dan capital) pada studi kasus di bank JATENG syariah ini dianggap sebagai sehat, pada analisis Risk profile dalam keadaan yang sehat karena rata berada peringkat ke 1 dan ke-3 maka dari itu bank jateng bisa mengatasi kredit macaet dengan baik dan seharusnya lebih ditingkatkan kembali agar para nasabah tetap menggunakn bank JATENG syariah. Sedangkan berdasarkan analisis GCG memiliki predikat yang cukup baik dalam menerapakna GCG tetapi harus lebih ditingkatkan kembali agar lebih efektif dan efisien.

Pada analisis Earning di bank JATENG syariah ini bisa diktakan baik dalam menjalankan kinerja perusahaan, sehingga harus dipertahankan dan harus bisa juga 
dalam keadaan yang sangat baik. Suapaya bisa meningkat kinerja dalam pengelolahn asst agar lebih baik lagi.

Dalam mengatasi biaya modal atau dalam analisis Capital bank JATENG syariah mendapatkan predikat ke-1, bahwa demikian bisa dikatakan bahwa bank JATENG syariah memiliki moda yang sangat bagus dan bisa memenuhi kebutuhan dan kewajiban dari segi usaha dan menutup resiko kerugian yang disebabkan perusahaan.

\section{REFERENSI}

Agustina, R. (2017). Penilaian Tingkat Kesehatan Perbankan Syariah Di Indonesia Dengan Metode RGEC. Al-Urban: Jurnal Ekonomi Syariah Dan Filantropi Islam, 1(1), 35-51.

Andraini, S. (2021). PENILAIAN TINGKAT KESEHATAN PERBANKAN SYARIAH DI INDONESIA DENGAN METODE RISK PROFILE GOVERNANCE EARNING CAPITAL (RGEC). PROCEEDINGS UNIVERSITAS PAMULANG, l(1).

Anik, A., \& Ningsih, S. (2020). Analisis Tingkat Kesehatan Bank Mandiri Syariah Dengan Metode Risk Profile, Good Corporate Governace, Earnings and Capital. Jurnal Ilmiah Ekonomi Islam, 6(3), 724-730.

Irham Fahmi. (2015). Manajemen Perbankan: Konvensional dan syariah. Jakarta: Mitra Wacana Media.

Mamu, M., Pelleng, F. A., \& Kelles, D. (2016). Analisis Tingkat Kesehatan Bank Bni Syariah, Tbk Dengan Menggunakan Metode Rgec. JURNAL ADMINISTRASI BISNIS (JAB), 4(2).

Pratikto, M. I. S., Qanita, A., \& Maghfiroh, R. U. (2019). Analisis Tingkat Kesehatan dan Potensi Financial Distress dengan Metode RGEC Pada BNI Syariah Tahun 2014-2018. El-Qist: Journal of Islamic Economics and Business (JIEB), 9(1), 87101.

Pratikto, M. I. S., Safitri, G. A., \& Basya, M. M. (2019). Analisis Tingkat Kesehatan Bank melalui Pendekatan RGEC (Risk Profile, Good Corporate Governance, Earning, Capital) Tahun 2014-2018 (Studi Pada PT Bank Bri Syariah (Persero) Tbk.). El-Qist: Journal of Islamic Economics and Business (JIEB), 9(2), 128-142.

Samanto, H., \& Hidayah, N. (2020). Analisis Penilaian Tingkat Kesehatan Bank dengan Metode RGEC Pada PT Bank BRI Syariah (Persero) 2013-2018. Jurnal Ilmiah Ekonomi Islam, 6(3), 709-715.

Saputra, J. S. (2017). Analisis tingkat kesehatan bank dengan menggunakan metode RGEC di PT. BPD Jateng tahun 2011-2015 (PhD Thesis). UIN Walisongo.

Sudarsono, H. (2008). Bank dan Lembaga Keuangan Syariah. UII Press: Ekonisia.

Umiyati, U., \& Faly, Q. P. (2015). Pengukuran kinerja bank syariah dengan metode RGEC. Jurnal Akuntansi Dan Keuangan Islam, 3(2), 185-201. 
Niqosiya: Journal of Economics and Business Research

Vol. 1 No. 1, Januari-Juni 2021: 94-109

Wahasusmiah, R., \& Watie, K. R. (2018). Metode RGEC: Penilaian Tingkat Kesehatan Bank Pada Perusahaan Perbankan Syariah. I-Finance: A Research Journal on Islamic Finance, 4(2).

Wiroatmodjo, P. (2009). Dasar penelitian dan Statistika. Jakarta: Universitas Indonesia UI-Press. 